\title{
NLRP3 inflammasome inhibitor MCC950 attenuates primary dysmenorrhea in mice via the NF-kB/COX-2/PG pathway
}

\author{
Biao Tang ${ }^{1,2^{*}} \mathbb{D}$, Dan Liu', Lingyu Chen ${ }^{1}$ and Yu Liu ${ }^{1}$
}

\begin{abstract}
Background: Primary dysmenorrhea (PD) constitutes a common gynecological disease among young women. The NLRP3 inflammasome may be activated and expressed in PD, but the mechanistic link between NLRP3

inflammasome activation and PD is still unclear.

Methods: To investigate the potential role of NLRP3 inflammasome activation in the pathogenesis of PD, 30 female Kunming mice without pregnancy were used for experiments. The PD mouse model was constructed by 11 days of successive co-treatment with estradiol and oxytocin. MCC950, a potent and specific small-molecule inhibitor of the NLRP3 inflammasome, was used to treat PD mice. The disease level was assessed by the writhing response and hot water tail-flick test. The levels of prostaglandin $E_{2}\left(P_{G} E_{2}\right)$ and prostaglandin $F_{2}$ alpha $\left(P_{G F}\right)$ in the uterine tissues of mice were detected by ELISA. The expression levels of protein and cytokines, including NLRP3, cysteine aspartic acid-specific protease 1 (caspase-1), interleukin (IL)-1 $\beta$, IL-18, nuclear factor kappa B (NF-kB) p65, phospho-NF-kB p65, and cyclooxygenase-2 (COX-2) were revealed by western blot analysis.
\end{abstract}

Results: MCC950 greatly ameliorated the writhing response induced by the combination of oxytocin and estradiol, with an increasing length of tail-flick latency. MCC950 also significantly decreased the levels of PGF $2 a$ and PGE 2 , and the expressions of NLRP3, caspase-1, IL-1 $\beta$, IL-18, phospho-NF-KB p65, NF-KB p65, and COX-2 in the uterus.

Conclusions: MCC950 markedly alleviated the pain and pathological damage in PD mice by inhibiting NLRP3 activation. The underlying mechanism may be related to hypoactive uterine inflammation via suppression of NLRP3 activation and the NF-KB/COX-2/PG pathway in uteruses of PD mice.

Keywords: Primary dysmenorrhea, Nucleotide-binding oligomerization domain-like receptor protein 3, Nuclear factor kappa B, Cyclooxygenase-2, Prostaglandins

\section{Background}

Primary dysmenorrhea (PD), a common gynecological disease among young women, constitutes functional dysmenorrhea without a definite gynecological pathological origin and seriously affects every aspect of the lives,

\footnotetext{
* Correspondence: biaotang@hnucm.edu.cn

${ }^{1}$ Department of Physiology, Medical School, Hunan University of Chinese Medicine, No.300 Xueshi Road, Changsa, China

${ }^{2}$ Hanpu Science \& Education District, Hunan province, Changsha 410208, China
}

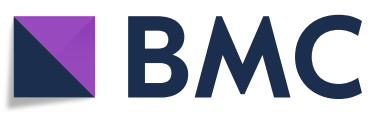

(c) The Author(s). 2020 Open Access This article is licensed under a Creative Commons Attribution 4.0 International License, which permits use, sharing, adaptation, distribution and reproduction in any medium or format, as long as you give appropriate credit to the original author(s) and the source, provide a link to the Creative Commons licence, and indicate if changes were made. The images or other third party material in this article are included in the article's Creative Commons licence, unless indicated otherwise in a credit line to the material. If material is not included in the article's Creative Commons licence and your intended use is not permitted by statutory regulation or exceeds the permitted use, you will need to obtain permission directly from the copyright holder. To view a copy of this licence, visit http://creativecommons.org/licenses/by/4.0/. The Creative Commons Public Domain Dedication waiver (http://creativecommons.org/publicdomain/zero/1.0/) applies to the data made available in this article, unless otherwise stated in a credit line to the data. work, and study of female patients [1]. Clinically, the main symptom of PD is menstrual pain.

Currently, excessive secretion of prostaglandins (PG) in uterine tissues has been proposed as a trigger for PD, though the mechanisms responsible for PD remain poorly understood [2]. Cyclooxygenase-2 (COX-2), a key enzyme involved in PG production, has its expression dramatically enhanced in the period of pre-menstruation. Subsequently, increased COX-2 converts arachidonic acid to PG, which induces spastic pain [3]. Nuclear factor kappa 
$\mathrm{B}(\mathrm{NF}-\mathrm{kB})$ is a crucial factor for the regulation of COX-2 [4]. Increasing studies have shown that the NF-kB/COX2/PG pathway plays a pathogenic role in $\mathrm{PD}$, which suggests that therapeutic interventions of the NF-kB/COX-2/ PG pathway can exert protective effects against PD $[5,6]$.

It has been reported that inflammation potently mediates the pathological process of PD. Activated macrophages produce a wide array of inflammatory cytokines, such as interleukin-1 $\beta$ (IL-1 $\beta$ ), IL-6, and tumor necrosis factor $\alpha$, which stimulate the synthesis and release of PG, leading to excessive contraction of uterine smooth muscles and ischemic injury in PD [7, 8]. As a core part of inflammation, the nucleotidebinding oligomerization domain-like receptor protein 3 (NLRP3) inflammasome is involved in a wide array of acute and chronic diseases, such as coronary heart disease, stroke, pneumonia, acute kidney injury, and viral hepatitis [9]. The assembly of the NLRP3 inflammasome as stimulated by NLRP3 irritants triggers proteolytic cleavage of dormant procaspase- 1 into active caspase- 1 , which converts the cytokines pro-IL-1 $\beta$ and pro-IL-18 into mature and biologically active IL$1 \beta$ and IL-18, respectively, leading to a cascade of deleterious inflammation [10]. Moreover, there is increasing evidence indicating that the NLRP3 inflammasome plays a regulatory role in the expression of COX-2 via the NF- $\mathrm{KB}$ pathway $[11,12]$. Our previous studies have found that the NLRP3 inflammasome can be activated and expressed in PD, and effective traditional electroacupuncture therapy to treat PD is associated with the inhibition of NLRP3 inflammasome activation [13]. However, the mechanistic link between NLRP3 inflammasome activation and PD is still unclear. Therefore, we constructed a PD mouse model to investigate whether inhibition of NLRP3 inflammasomes through the NF-kB/COX-2/PG pathway exerts protective effects against $\mathrm{PD}$ induced by a combination of estradiol and oxytocin.

\section{Materials and methods \\ Animals}

Thirty healthy female nonpregnant Kunming mice (18$22 \mathrm{~g}, 6-8$ weeks old) in the same cycle were purchased from Hunan Slack Jingda Lab Animal Co., Ltd. [Hunan, China, SYXK (Xiang) 2013-0004] All animals were kept on natural circadian rhythms at optimal temperature $\left(20^{\circ} \mathrm{C}-25^{\circ} \mathrm{C}\right)$ and humidity $(50-70 \%)$, with free access to water and food. After a week, the 30 mice were divided into three groups (Saline group, PD group, and MCC950 group), with 10 mice in each group. All experimental procedures were approved by the Instructive Notions with Respect to Caring for Laboratory Animals promulgated by the Ministry of Science and Technology of China in 2006.

\section{Pharmaceutical and main reagents}

Oxytocin was purchased from Shanghai Hefeng Pharmaceutical Co., Ltd. (No. H31020850, Shanghai, China), and estradiol (No. J20130009, Bayer, Germany) was purchased from Bayer. Both are approved by the State Food and Drug Administration (SFDA). Other reagents and materials included MCC950 (CP-456773, Selleck, USA; CAS number: 210826-40-7; formula: C20H24N2O5S; molecular weight: $404.48 \mathrm{~g} / \mathrm{mol}$ ), mouse $\mathrm{PGF}_{2 \alpha}$ kit (production lot number: 516011, Cayman Chemical, USA), mouse $\mathrm{PGE}_{2}$ kit (production batch number: 514010, Cayman Chemical, USA), BCA protein quantification kit (production lot number: A53225, Thermo, USA), NLRP3 antibody (production batch number: NBP2-12446, Novus Biological, USA), phospho-NF-kB-p65 antibody (production batch number: \#3033, Cell Signaling Technology, USA), NF-кB-p65 antibody (production lot number: \#4746, Cell Signaling Technology, USA), IL-1 $\beta$ antibody (production batch number: ab9787, Abcam, UK), IL-18 antibody (production lot number: ab191860, Abcam, UK), caspase-1 antibody (production batch number: NBP1-45433, Novus Biological, USA), beta-actin mouse monoclonal antibody (production lot number: \#4211, Cell Signaling Technology, USA), goat anti-rabbit secondary antibody (production batch number: AP132P, Merck Millipore, Germany), and goat anti-mouse secondary antibody (production lot number: AP124P, Merck Millipore, Germany).

\section{Construction of the PD mouse model}

Mice in the Saline group were given $0.2 \mathrm{ml}$ saline by gavage at 18:00 for 10 days and intraperitoneally injected with $0.2 \mathrm{ml}$ saline on the 11th day. To mimic PD in vivo, mice in the PD group and MCC950 group were given estradiol $(0.2 \mathrm{mg} / \mathrm{ml}, 0.2 \mathrm{ml} /$ day $)$ by gastric gavage at 18 : 00 for 11 days; this was used to synchronize the uterine cycles. The oxytocin receptor (OTR) overexpressed when activated by estrogen, and the concentrations of OTR were used to determine the sensitivity of endometrium to oxytocin stimulation $[14,15]$. After gastric gavage of estradiol for $2 \mathrm{~h}$, intraperitoneal injection of 0.2 $\mathrm{ml} \mathrm{MCC950}(2 \mathrm{mg} / \mathrm{ml})$ was given to mice for 10 days in the MCC950 group. On the 11th day, both groups were given estradiol via intraperitoneal injection and $0.2 \mathrm{ml}$ oxytocin $(2 \mathrm{U} / \mathrm{ml})$ within an hour [16]. Oxytocin is a small peptide hormone that stimulates uterine contractions by functionally coupling to the OTR to induce dysmenorrhea. This model of dysmenorrhea in mice has been in use for several years [17, 18]. All mice were fasted for $12 \mathrm{~h}$ before gavage. After daily intervention, they had free access to water and food.

\section{Measurement of writhing times}

To assess the writhing response, we recorded 20-min writhing times and the writhing latency of mice. 
(Writhing response: the abdomen of the mouse was contracted and concave with straight hind limbs; writhing latency: from intraperitoneal injection of oxytocin to the first writhing reaction [19].)

\section{Thermal tail-flick test}

The thermal tail-flick test was used to assess the nociceptive reflex response to thermal stimulus in treated animals. When the pain threshold of mice is exceeded, they use an effective tail flick escape [20]. The thermal tail-flick test of acute pain was performed on the 11th day after pharmaceutical injection. Each experimental mouse was placed in a fixator with the tail exposed. When it was stable, $1 / 3$ rd of the tail was placed in hot water at $52^{\circ} \mathrm{C}$. The tail-flick latency (from the tail entering the water to exiting) was measured with a stopwatch (accuracy: $0.01 \mathrm{~s}$ ) for 4 consecutive times each with an interval of $1 \mathrm{~min}$ [21]. Each tail was measured in triplicate, and the average value was calculated.

\section{Enzyme-linked Immunosorbent assay (ELISA)}

The levels of $\mathrm{PGF}_{2 \alpha}$ and $\mathrm{PGE}_{2}$ in uterine tissues were determined with an ELISA. The supernatant including total protein (TP) was obtained by homogenization and centrifugation from the same segment of ipsilateral uteruses of 5 mice randomly selected in each group. Each sample was incubated overnight with diluent and standard solution at $4{ }^{\circ} \mathrm{C}$. Subsequently, the plate was washed and Ellman's reagent was added, it was reacted at $4{ }^{\circ} \mathrm{C}$ in the dark for $60 \mathrm{~min}$, and the absorbance value of each hole at $412 \mathrm{~nm}$ was measured. The concentration of $\mathrm{PGF}_{2 \alpha}$ was determined by the standard curve according to absorbance value of the standard hole and its corresponding concentration. The TP in collected supernatant was quantified by a BCA protein quantitative kit. Each sample was added with prepared standard compound based on the gradient method and incubated with working solution at $37^{\circ} \mathrm{C}$ for $30 \mathrm{~min}$, then the absorbance value of each hole at $412 \mathrm{~nm}$ was measured. The concentration of TP was determined by the standard curve according to absorbance value of the standard hole and its corresponding concentration. The ratio between $\mathrm{PGF}_{2 \alpha} / \mathrm{PGE}_{2}$ and TP indicated the content of $\mathrm{PGF}_{2 \alpha}$ in the supernatant of uterine homogenate. All procedures were according to the manufacturer's protocol.

\section{Western blotting}

The supernatant containing TP of the collected mouse uterine tissues was separated by homogenization using liquid nitrogen and $1 \mathrm{ml}$ cold lysis buffer for $10 \mathrm{~min}$, followed by centrifugation at $4{ }^{\circ} \mathrm{C}$ and $12,000 \mathrm{r} / \mathrm{min}$ for $10 \mathrm{~min}$. To fully denature TP, the supernatant was added with sample buffer and heated in a boiling water bath for $10 \mathrm{~min}$. The calculation and balance of protein concentration, together with the protein standard curve, was based on protein quantification via a BCA protein quantification kit. Samples were subjected to electrophoresis, membrane transfer, and blocking. Immunoblot analysis was performed with specific primary antibodies followed by secondary antibody: NLRP3 (1:1000), caspase-1 (1:500), IL-1 $\beta$ (1:1000), IL-18 (1:1000), phospho-NF-кB p65 (1:1000), NF-кB p65 (1:1000), COX-2 (1:1000), or $\beta$-actin (1:5000). Blots were incubated in enhanced chemiluminescence reagent, and exposed on radiographic film. The western blots were scanned and the density of the target bands was quantified by Quantity One software. The results for each protein were normalized against the intensity of $\beta$-actin in each sample. The relative protein content was expressed as arbitrary units.

\section{Statistical analysis}

All data were analyzed using the SPSS version 22.0 statistical analysis package. All data are expressed as means \pm standard deviation (S.D.) and were analyzed by twotailed, unpaired, Student's $t$-test or ANOVA if appropriate. A value of $p<0.05$ was considered statistically significant.

\section{Results}

MCC950 inhibited the activation of NLRP3

inflammasomes in uterine tissues of mice with PD

Uterine tissues were examined by western blotting to detect the levels of NLRP3, cleaved-caspase-1 (p20) and activated forms of IL- $1 \beta$, and IL-18. Western blotting analyses of the uterine tissues of saline-injected mice showed low levels of NLRP3, cleaved-caspase-1 (p20) and activated forms of IL-1 $\beta$, and IL-18. In contrast, within $20 \mathrm{~min}$ after oxytocin injection, the levels of NLRP3, cleaved-caspase-1 (p20), and activated forms of IL-1 $\beta$ and IL-18 in uterine tissues of the PD group increased significantly (Fig. $1, P<0.01$ ), but they did not increase in the MCC950 group (Fig. $1, P<0.01$ ).

\section{MCC950 reduced writhing times and prolonged writhing latency and tail-flick latency in mice with PD}

To investigate whether NLRP3 inflammasome activation promotes PD pain, we first examined the effect of an NLRP3 inhibitor on PD induced by estradiol and oxytocin in mice. There was no writhing response in the Saline group, while mice in the PD group and MCC950 group showed alert writhing responses. Within 20 min after oxytocin injection, the writhing response numbers of the PD group significantly increased (Fig. $2 \mathrm{a}, P<0.01$ ) with abbreviated tail-flick latency (Fig. $2 c, P<0.01$ ) compared with the Saline group. Compared with the PD control group, the writhing numbers of the MCC950 group were significantly decreased (Fig. 2a, $P<0.01$ ), and the writhing 

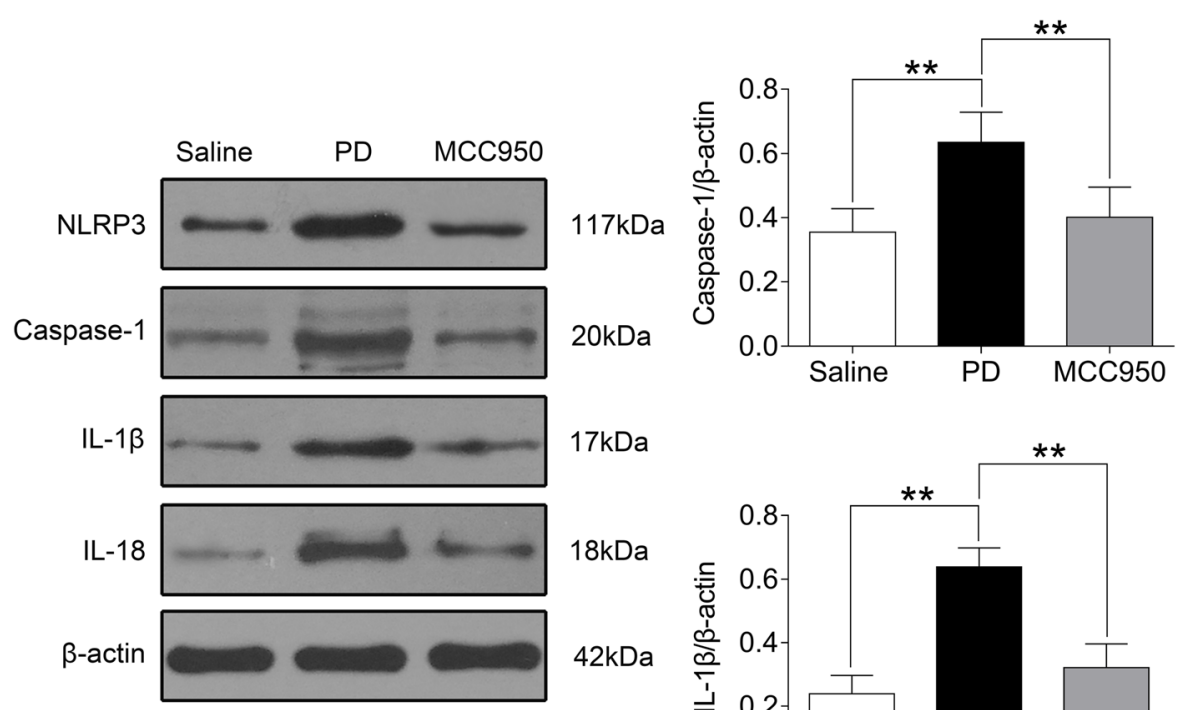

$17 \mathrm{kDa}$
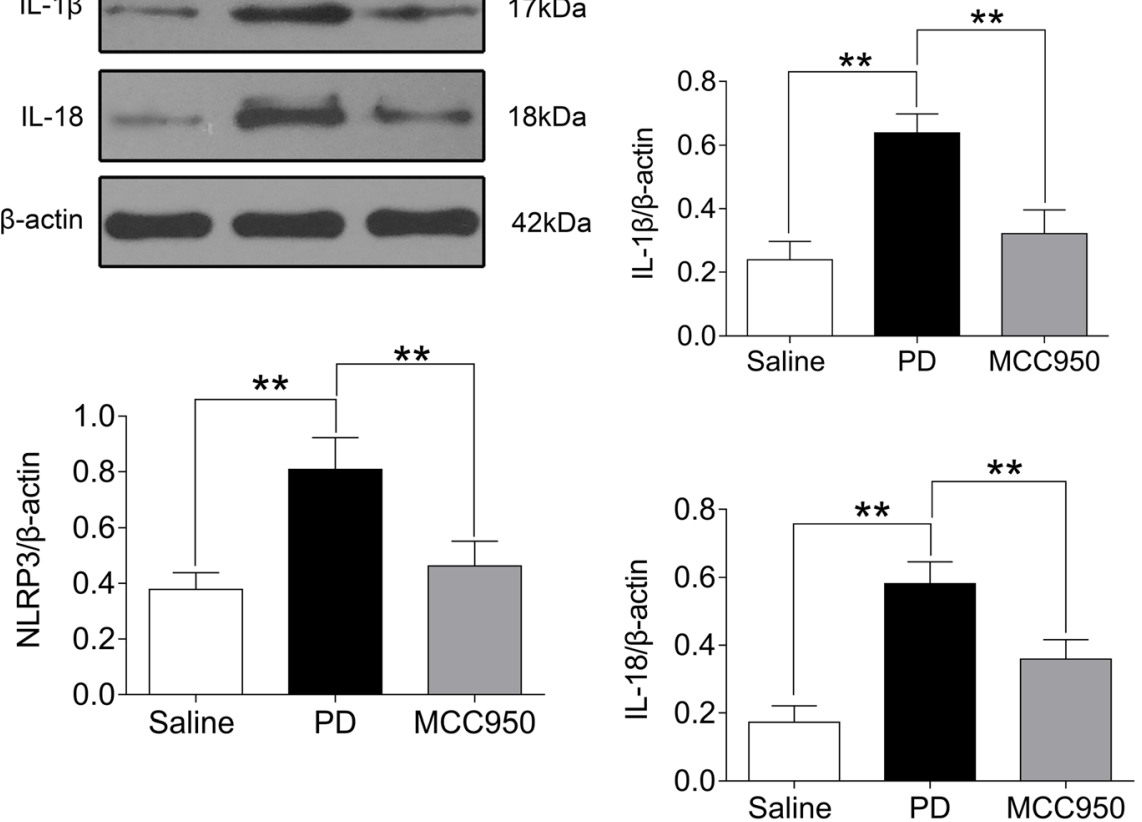

Fig. 1 Comparison of NLRP3, cleaved-caspase-1 (p20) and activated forms of IL-1 3 and IL-18 proteins in mouse uteruses among groups. In the saline group, mice were treated with saline. In the PD group, estradiol $(0.2 \mathrm{mg} / \mathrm{ml})$ and oxytocin $(2 \mathrm{U} / \mathrm{ml})$ induced a significant decrease of NLRP3, caspase-1, IL-1 $\beta$, and IL-18 proteins levels compared to the saline group. MCC950, an inhibitor of NLRP3, suppressed these protein levels according to western blotting. The data represent the mean \pm SD $(n=5)$ of the relative protein content. The asterisks above the bars indicate significant differences compared to the PD group. ${ }^{* *} P<0.01$

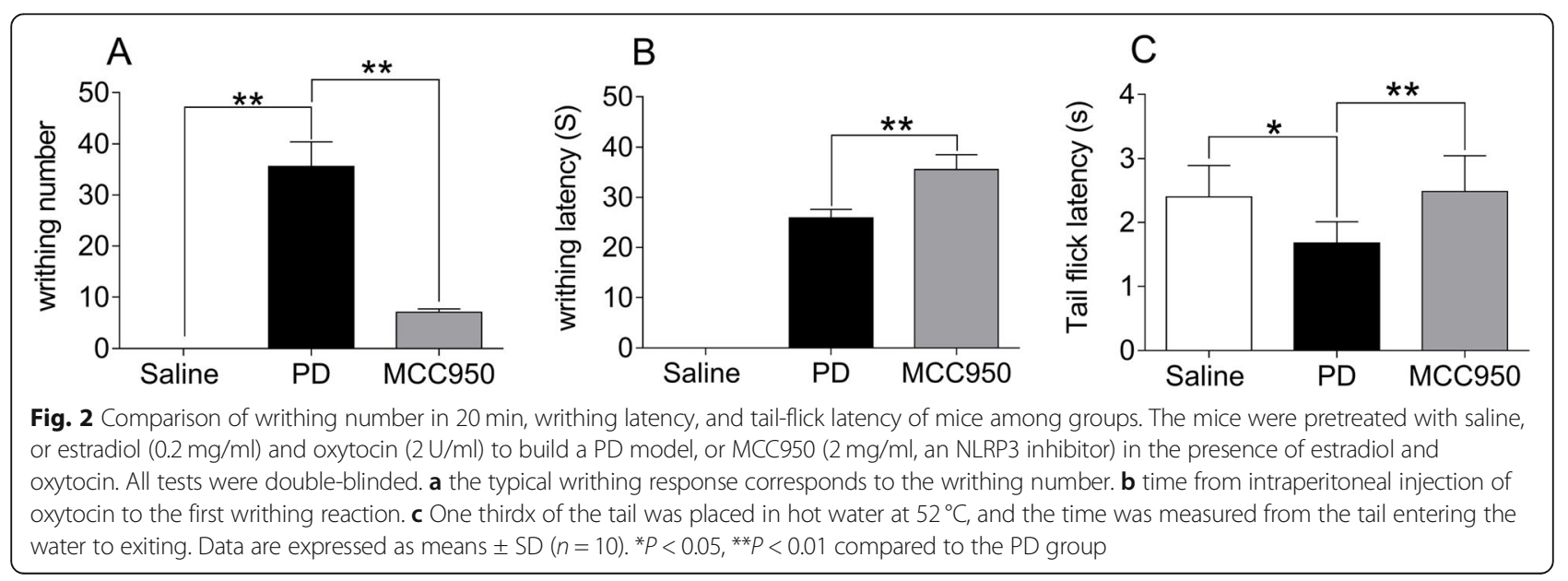


latency and tail-flick latency were increased (Fig. 2b and Fig. $2 c, P<0.01$ ) within 20 min (Fig. 2).

\section{MCC950 inhibited production of PG in uterine tissues of mice with PD}

PG is known to play a role in PD as a mediator of inflammation. We next tested whether an NLRP3 inhibitor can regulate PG in the presence of PD. Compared with the Saline group, $\mathrm{PGF}_{2 \alpha}$ and $\mathrm{PGE}_{2}$ in the $\mathrm{PD}$ group were significantly increased (Fig. $3, P<0.05$ or $P<0.01)$. Compared with the PD group, the levels of $\mathrm{PGF}_{2 \alpha}$ and $\mathrm{PGE}_{2}$ in the MCC950 group were decreased (Fig. 3, $P<0.05$ ).

\section{MCC950 decreased the level of COX-2 in uterine tissues of mice with PD}

Next, we determined the effect of NLRP3 inflammasome inhibition on COX-2 as an upstream regulatory protein of PG in PD mice. As expected, the protein level of COX-2 in the uterine tissues of mice in the Saline group was very low and could not be detected by western blotting. Compared with the Saline group, the COX-2 protein level in the uterine tissues of the PD group was significantly increased (Fig. $4, P<0.01$ ). Subsequently, we confirmed that the levels of COX-2 were decreased significantly in the MCC950 group compared with those of PD group (Fig. $4, P<0.01$ ).

\section{MCC950 suppressed activation of the NF-KB pathway in uterine tissues of mice with PD}

To confirm whether the effect of NLRP3 inflammasomes on PD-induced pain was related to NF- $\mathrm{kB}$ p65, we investigated NF- $\mathrm{kB}$ p65 phosphorylation by western blotting. Compared with the Saline group, the protein levels of phospho-NF- $\mathrm{B}$ p 65 and NF- $\mathrm{B}$ p65 in the PD group were significantly increased (Fig. $5, P<0.01$ ). Compared with the PD group, the protein levels of phospho-NF-kB p65 and NF-kB p65 in the MCC950 group were decreased significantly (Fig. 5, $P<0.01$ ).

\section{Discussion}

It has become clear that the NLRP3 inflammasome is involved in a broad spectrum of gynecological diseases such as cervical cancer, preterm labor, postpartum inflammation, and mycoplasma and chlamydia infection $[22,23]$. Our study found that NLRP3, cleaved-caspase-1 (p20) and activated forms of IL-1 $\beta$ and IL-18 were dramatically increased in mice with PD, which could be reversed by intervention with MCC950, a specific inhibitor of NLRP3 that only inhibits the activation of caspase- 1 and the processing of IL-1 $\beta$ and IL-18 [24]. Recent reports show that MCC950 dose-dependently decreases the efficiency of NLRP3 NACHT domain immunoprecipitation, which agrees with our results $[25,26]$. These results suggested that the NLRP3 inflammasome is expressed and activated in the uteruses of PD mice, which may offer substantial promise in developing new therapeutics for PD. Emerging evidence suggests that NLRP3 inflammasome activation occurs in endometritis cells, while inhibiting NLRP3 inflammasomes generates a significant ameliorative role in the pathological process of endometritis [27]. Moreover, the activation of the NLRP3 inflammasome aggravates the degree of inflammatory infiltration in gynecological diseases such as endometritis and pelvic inflammatory disease, which indicates that therapeutic interventions via the NLRP3 inflammasome may be a novel strategy for treating PD $[28,29]$. Therefore further investigation is warranted to explore the role of the NLRP3 inflammasome in PD.

In our study, mice in the PD group presented obvious writhing responses via administration of oxytocin. In contrast, writhing times were significantly decreased and tail-flick latency was noticeably elongated in the MCC950 group. The writhing response measures pain in a direct way, and the tail-flick latency indirectly evaluates
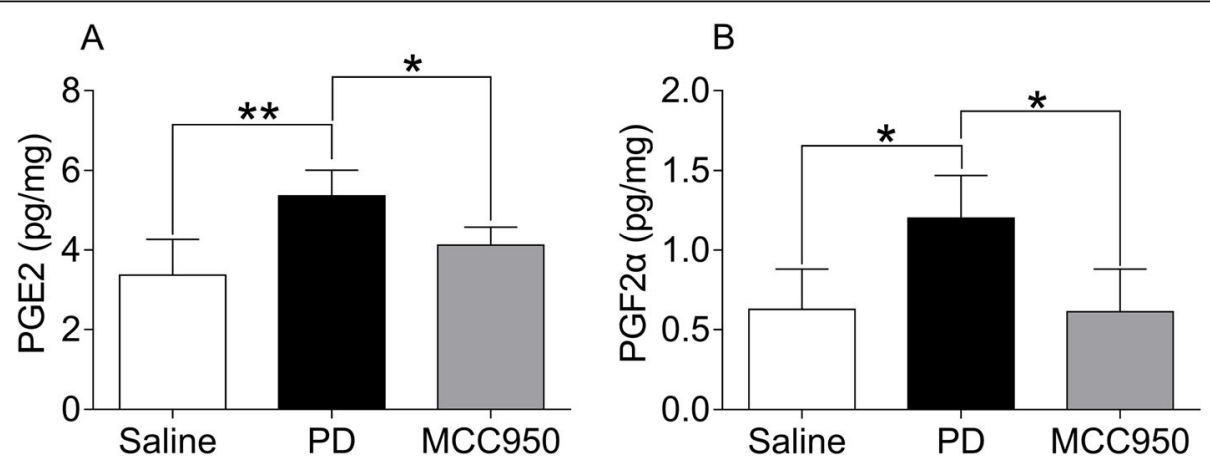

Fig. 3 Comparison of $\mathrm{PGE}_{2}$ and $\mathrm{PGF}_{2 a}$ in mouse uteruses among each group. The mice were pretreated with saline, or estradiol $(0.2 \mathrm{mg} / \mathrm{ml})$ and oxytocin $(2 \mathrm{U} / \mathrm{ml})$ to build a PD model, or MCC950 $(2 \mathrm{mg} / \mathrm{ml}$, an NLRP3 inhibitor) in the presence of estradiol and oxytocin. a Levels of PGE 2 and b levels of $\mathrm{PGF}_{2 a}$ were assayed by ELISA. The results are presented as means $\pm \mathrm{SD}(n=5)$. ${ }^{*} P<0.05,{ }^{* *} P<0.01$ compared to the PD group 

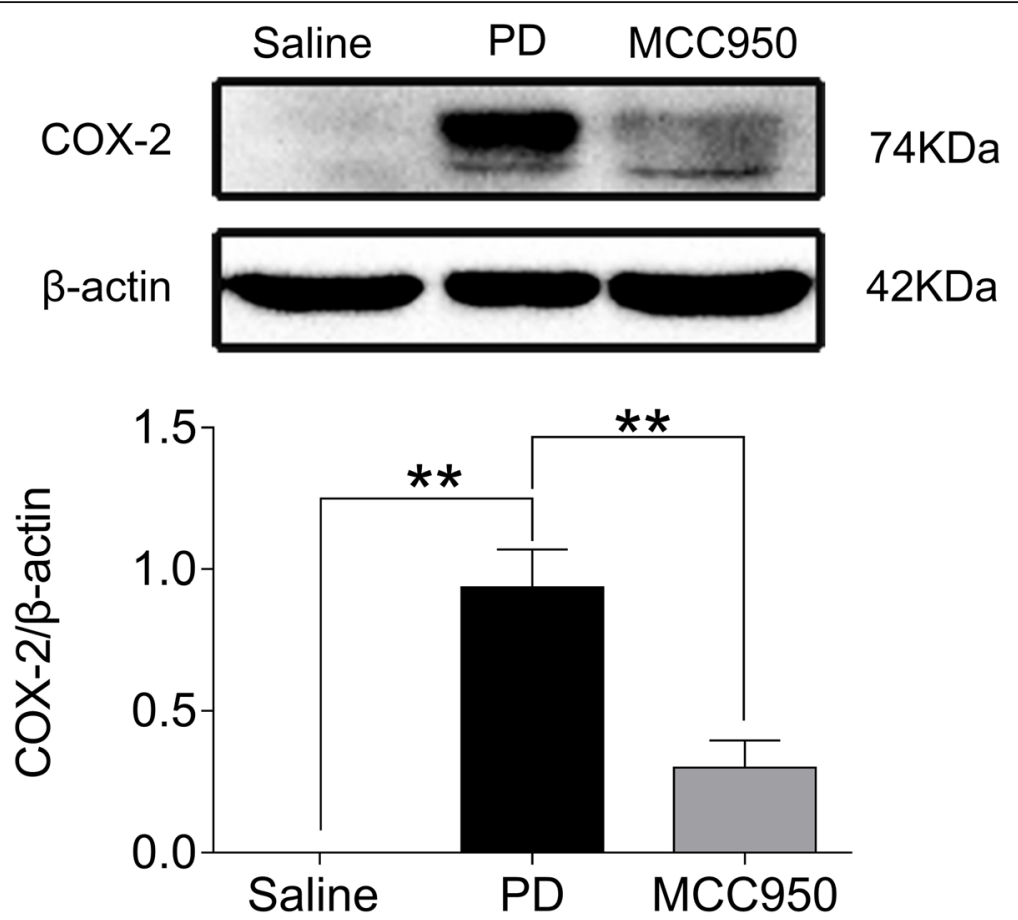

Fig. 4 Comparison of COX-2 protein expression in mouse uteruses among groups. No upregulation of COX-2 expression occurred in the saline group ( $\beta$-actin used as control). Western blot analyses of COX-2 expression in mice co-stimulated with estradiol $(0.2 \mathrm{mg} / \mathrm{ml})$ and oxytocin ( $2 \mathrm{U} / \mathrm{ml})$ in the PD group. A significant decrease of COX-2 protein expression occurred compared to the saline group. MCC950, an inhibitor of NLRP3, suppressed COX-2 protein expression. Data are expressed as means \pm SD $(n=5)$. ${ }^{* *} P<0.01$ compared to the PD group

pain threshold changes [30, 31]. The results suggested that NLRP3 suppression exerted an important role in both the anti-inflammatory and analgesic response against PD. Further, we concentrated on the NF-kB/ COX-2/PG pathway to elucidate the potential mechanism of PD.

The $\mathrm{PGF}_{2 \alpha}$ and $\mathrm{PGE}_{2}$ levels of mice uteruses in the PD group robustly increased, while they significantly decreased through MCC950 intervention. It has been reported that both $\mathrm{PGF}_{2 \alpha}$ and $\mathrm{PGE}_{2}$ are the primary members of prostaglandins that play a critical role in the inflammatory process. The levels of $\mathrm{PGF}_{2 \alpha}$ and $\mathrm{PGE}_{2}$ in the uterine tissues and peripheral blood of PD patients are higher than normal [2]. Additionally, numerous studies have illustrated that high levels of $\mathrm{PGF}_{2 \alpha}$ lead to pathological pain responsible for uterine contraction, hematological alterations, and the accumulation of acidic metabolites [32]. In this study, we found that $\mathrm{PGF}_{2 \alpha}$ and $\mathrm{PGE}_{2}$ in uterine tissues of PD mice markedly decreased by inhibiting NLRP3 inflammasomes.

COX-2, an important limiting rate enzyme participating in PG synthesis, exhibits a tight relationship with uterine inflammation [33], while upstream, NF- $\mathrm{kB}$ mediates the expression and activation of COX-2. We

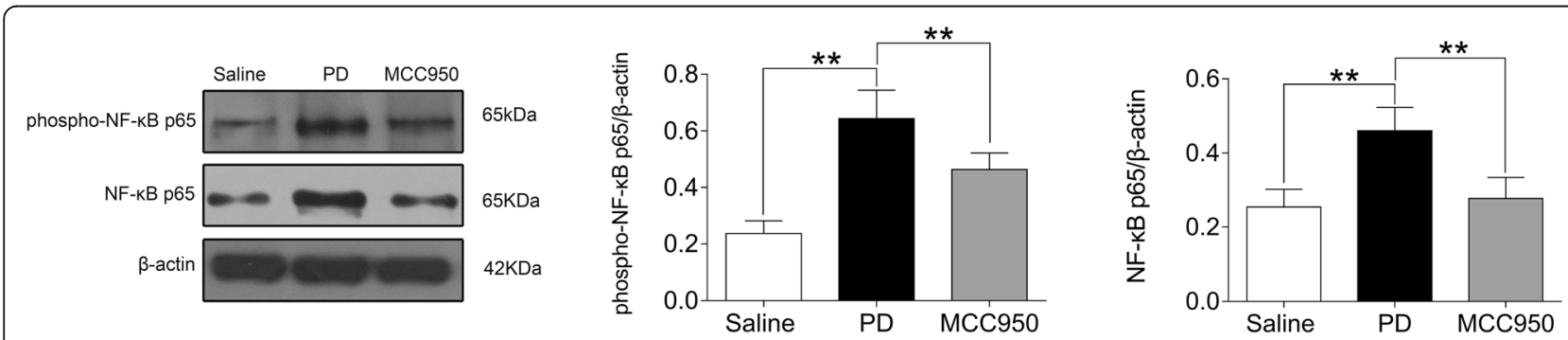

Fig. 5 Comparison of phospho-NF-KB p65 and NF-KB p65 protein expression in mouse uteruses among groups. In the PD group, estradiol (0.2 $\mathrm{mg} / \mathrm{ml}$ ) and oxytocin $(2 \mathrm{U} / \mathrm{ml})$ induced a significant decrease of phospho-NF-KB p65 and NF-KB p65 protein expression compared to the saline group. MCC950, an inhibitor of NLRP3, suppressed these increases in protein expression according to western blotting The data represent the means $\pm \mathrm{SD}(n=5)$ of the relative protein content. ${ }^{*} P<0.01$ compared to the PD group 
measured the levels of NF- $\mathrm{KB}$ and COX-2 in the uterine tissues of mice after MCC950 intervention. The results showed that COX-2 in the Saline group was scarce, while it significantly increased in the uterine tissues of PD mice. Furthermore, MCC950 intervention reversed the potent increase of COX-2 protein levels in PD mice. Under physiological conditions, COX-2 exists at a very low level, but it is elevated by inflammatory stimuli. Studies have shown that the expression of COX-2 goes up before menstruation, which catalyzes arachidonic acid into active PG, resulting in spasmodic pain. Nonsteroidal anti-inflammatory drugs, such as ibuprofen, play a profound role in treating the symptoms of PD via COX2 inhibition with a subsequent decrease of PG [34].

As an important transcriptional regulator, NF- $\mathrm{kB}$ plays a crucial role in PD via regulation of COX-2 [35]. In general terms, the phosphorylation of the NF- $k B$ subunits has a profound effect on the function of NF- $\mathrm{kB}$ and promotes its translocation [36, 37]. As detected by western blot analysis, the levels of phospho-NF- $\mathrm{kB}$ p65 and NF- $\mathrm{B}$ p 65 significantly increased in the uterine tissues of mice with PD. It is well known that NF- $k B$ is needed during the priming phase to induce NLRP3 and pro-IL1B expression [38, 39]. However, a report on nonalcoholic fatty liver disease showed that MCC950 can reduce inflammation and NF- $\mathrm{kB}$ activation by inhibiting NLRP3 [40]. It has been also shown that IL-1 $\beta$, a downstream inflammatory factor of NLRP3, can promote the expression of NF- $\mathrm{KB}$ by phosphorylating serines 316,529 and 536 of the p65 subunit to regulate the target gene [41]. This is consistent with our results. MCC950 intervention strongly attenuated the activation of phosphoNF- $\kappa B$ p 65 and NF- $\kappa B$ p 65 in PD mice, which indicated that the NF-kB pathway plays a pathogenic role in PD, and that inhibiting NLRP3 inflammasomes could downregulate NF- $\mathrm{kB}$ activation. Previous studies have shown that some NF- $\mathrm{kB}$ site sequences are located in the flanking region of the $5^{\prime}$ end of the COX-2 coding sequence. NF- $\mathrm{kB}$ induce the activation of $\mathrm{COX}-2$ by binding to these sites, which indicates that NF- $\mathrm{kB}$ is a key factor that regulates COX-2 $[42,43]$. It has also been reported that NF-kB induces the activation of COX-2 genes in primary dysmenorrhea [44], and some studies have shown that the NLRP3 inflammasome upregulates NF$\kappa \mathrm{B}$ activation and promotes COX-2 expression [45]. Moreover, it has been reported that NLRP3 inflammasomes could be responsible for mediating the albumin effect on activating the COX-2/mPGES-1/PGE2 cascade, but the role of NF-kB in this case is not known [12]. The effect of NLRP3 on COX-2 is not clear, but we think that NLRP3 regulates COX-2 through the NF- $\mathrm{kB}$ pathway, and the NLRP3 inflammasome might be involved in the pathological progression of PD through the NF-kB/COX-2/PG pathway. In addition, it has been reported that COX-2 has an effect on NLRP3 and NLRP3 inflammasome activation that is regulated by dephosphorylation of COX-2 modified by PP2A [46], and COX-2 mediateds the enhancement of lipopolysaccharide-induced pro-IL-1 $\beta$ and NLRP3 expression by increasing NF-kB activation and enhancing caspase- 1 activation by increasing damaged mitochondria [47]; these effects are inhibited by the COX-2 inhibitor celecoxib. It has also been $\mathrm{s}$ reported that PTUPB, a dual COX-2 and sEH inhibitor, also inhibits the activation of NLRP3 inflammasomes [48, 49]. We speculate that MCC950 might reduce inflammation by blocking the positive feedback of COX-2 on NLRP3 inflammasomes. However, NLRP3 inflammasome activation is inhibited through its COX-2 metabolite, PGE2EA, and this effect is inhibited by celecoxib [50]. At present, the relationship between NLRP3 inflammasomes and COX-2 is not clear in PD and needs further research in the future. This study is potentially limited in that we mainly measured proteins levels by western blotting and ELISA rather than gene and transcription levels. However, since protein expression is the outcome of gene. Activity, we can preliminarily determine the role of these proteins and corresponding genes in PD by measuring protein levels and deducing its mechanism.

\section{Conclusions}

In summary, activation of NLRP3 inflammasomes induced deleterious effects in PD mice, and therapeutic interventions targeting NLRP3 inflammasomes via the NF$\kappa \mathrm{B} / \mathrm{COX}-2 / \mathrm{PG}$ pathway mitigated the agonizing pain responsible for PD. This novel finding of an inflammatory effect of NLRP3 inflammasomes in PD contributes to our understanding of the disease and provides a promising new target for PD intervention.

\section{Abbreviations}

PD: Primary dysmenorrhea;; NLRP3: Nucleotide-binding oligomerization domain-like receptor protein 3; Caspase-1: Cysteinyl aspartate-specific protease 1 ;i IL-1 $\beta$ : Interleukin-1 $\beta_{; ;}$IL-18: Interleukin-18; NF-kB: Nuclear factor kappa $B_{i ;}$ COX-2: Cyclooxygenase-2; PGE : Prostaglandin $E_{2 i "}$

$\mathrm{PGF}_{2 \mathrm{a}}$ : Prostaglandin $\mathrm{F}_{2}$ alpha; ELISA: Enzyme-Linked Immunosorbent Assay;" TP: Total protein;

\section{Acknowledgments}

We thank the members of our laboratory for their technical help.

\section{Authors' contributions}

Biao Tang: designed and conducted the experiments, analyzed and interpreted the data, and wrote the main manuscript; Dan Liu: conceived and wrote the main manuscript; Lingyu Chen: conducted the experiments and analyzed and interpreted the data; Yu Liu: conducted the statistical analyses. The authors read and approved the final manuscript.

\section{Funding}

This work was supported by the Scientific Research Fund of Hunan Provincial Education Department (No. 19B436), the Open Fund of the Domestic Firstclass Discipline Construction Project of Chinese Medicine of Hunan University of Chinese Medicine (No. 2018ZYX05), and the First-class Discipline 
Construction Project of basic medicine in 13th Five-Year Plan of Hunan University of Chinese Medicine (06).

\section{Availability of data and materials}

The data that support the findings of this study are available from the corresponding author upon request.

\section{Ethics approval and consent to participate}

All procedures were approved by the Institutional Animal Care and Use Committee at Hunan University of Chinese Medicine.

\section{Consent for publication}

Not applicable.

\section{Competing interests}

The authors declare no conflicts of interest.

\section{Received: 27 March 2020 Accepted: 18 June 2020} Published online: 24 June 2020

\section{References}

1. Li R, Li B, Kreher DA, Benjamin AR, Gubbels A, Smith SM. Association between dysmenorrhea and chronic pain: a systematic review and metaanalysis of population-based studies. Am J Obstet Gynecol. 2020. https://doi. org/10.1016/j.ajog.2020.03.002.

2. Haidari F, Homayouni F, Helli B, Haghighizadeh MH, Farahmandpour F. Effect of chlorella supplementation on systematic symptoms and serum levels of prostaglandins, inflammatory and oxidative markers in women with primary dysmenorrhea. Eur J Obstet Gynecol Reprod Biol. 2018;229: 185-9.

3. Sun L, Liu LN, Li JC, Lv YZ, Zong SB, Zhou J, et al. The essential oil from the twigs of Cinnamomum cassia Presl inhibits oxytocin-induced uterine contraction in vitro and in vivo. J Ethnopharmacol. 2017:206:107-14.

4. Shukla V, Kaushal JB, Sankhwar P, Manohar M, Dwivedi A. Inhibition of TPPP3 attenuates $\beta$-catenin/NF-KB/COX-2 signaling in endometrial stromal cells and impairs decidualization. J Endocrinol. 2019;240:417-29.

5. Wu CM, Chen PC, Li TM, Fong YC, Tang CH. Si-Wu-tang extract stimulates bone formation through PI3K/Akt/NF-KB signaling pathways in osteoblasts. BMC Complement Altern Med. 2013;13:277.

6. Chen Y, Cao Y, Xie Y, Zhang X, Yang Q, Li X, et al. Traditional Chinese medicine for the treatment of primary dysmenorrhea: how do Yuanhu painkillers effectively treat dysmenorrhea? Phytomedicine. 2013;20:1095-104.

7. Barcikowska Z, Rajkowska-Labon E, Grzybowska ME, Hansdorfer-Korzon R, Zorena K. Inflammatory markers in dysmenorrhea and therapeutic options. Int J Environ Res Public Health. 2020;17:1191.

8. Kannan P, Cheung KK, Lau BW. Does aerobic exercise induced-analgesia occur through hormone and inflammatory cytokine-mediated mechanisms in primary dysmenorrhea? Med Hypotheses. 2019;123:50-4.

9. Jiang H, Gong T, Zhou R. The strategies of targeting the NLRP3 inflammasome to treat inflammatory diseases. Adv Immunol. 2020;145:55-93.

10. Yang L, Mizuochi T, Shivakumar P, Mourya R, Luo Z, Gutta S, et al. Regulation of epithelial injury and bile duct obstruction by NLRP3, IL-1R1 in experimental biliary atresia. J Hepatol. 2018;69:1136-44.

11. Gao $Y, L v X$, Yang $H$, Peng $L, C i X$. Isoliquiritigenin exerts antioxidative and anti-inflammatory effects via activating the KEAP-1/Nrf2 pathway and inhibiting the NF-KB and NLRP3 pathways in carrageenan-induced pleurisy. Food Funct. 2020. https://doi.org/10.1039/c9fo01984g.

12. Zhuang $Y$, Zhao F, Liang J, Deng $X$, Zhang $Y$, Ding G, et al. Activation of COX-2/mPGES-1/PGE2 cascade via NLRP3 inflammasome contributes to albumin-induced proximal tubule cell injury. Cell Physiol Biochem. 2017;42: 797-807.

13. Liu $Y$, Wang $Y Q$, Chen $L Y, M o B Q$, Wu XX, Xiao $Y$, et al. Effect of electroacupuncture on NF-KB and NLRP3 inflammasome in uterine tissues of rats with primary dysmenorrhea. J Acupunct Tuina Sci. 2019;17:215-22.

14. Li M, Bi J, Lv B, Zheng W, Wang Z, Xiao W, et al. An experimental study of the anti-dysmenorrhea effect of Chinese herbal medicines used in Jin Gui Yao Lue. J Ethnopharmacol. 2019;245:112181.

15. Hulls CM, Lentle RG, Chua WH, Suisted P, King QM, Chagas JAB, et al. Spatiotemporal Mapping of the Contracting Gravid Uterus of the Rabbit Shows Contrary Changes With Increasing Gestation and Dosage With Oxytocin. Front Endocrinol (Lausanne). 2019;10:802.
16. Yang $L, C a o ~ Z, Y u B$, Chai $C$. An in vivo mouse model of primary dysmenorrhea. Exp Anim. 2015;64:295-303.

17. Jesuíno FWDR, Reis JP, Whitaker JCP, Campos A, Pastor MVD, Cechinel Filho $V$, et al. Effect of Synadenium grantii and its isolated compound on dysmenorrhea behavior model in mice. Inflammopharmacology. 2019;27: 613-20.

18. Peng Y, Zheng X, Fan Z, Zhou H, Zhu X, Wang G, et al. Paeonol alleviates primary dysmenorrhea in mice via activating CB2R in the uterus. Phytomedicine. 2020;68:153151.

19. Wei $Y$, Ma T, Wang H, Xing J, Wang Y, Gu Z, et al. Extracts of compound Muniziqi granule suppressed uterus contraction and ameliorated oxytocininduced primary dysmenorrhea. J Ethnopharmacol. 2018;223:33-40.

20. Schuster DJ, Metcalf MD, Kitto KF, Messing RO, Fairbanks CA, Wilcox GL. Ligand requirements for involvement of PKC $\varepsilon$ in synergistic analgesic interactions between spinal $\mu$ and $\delta$ opioid receptors. Br J Pharmacol. 2015; 172:642-53.

21. Baeta-Corral R, Defrin R, Pick CG, Giménez-Llort L. Giménez-Llort, tail-flick test response in $3 \times \mathrm{Tg}-\mathrm{AD}$ mice at early and advanced stages of disease. Neurosci Lett. 2015;600:158-63.

22. Pontillo A, Bricher P, Leal VN, Lima S, Souza PR, Crovella S. Role of inflammasome genetics in susceptibility to HPV infection and cervical cancer development. J Med Virol. 2016;88:1646-51.

23. Zhao G, Jiang $K$, Yang $Y$, Zhang $T$, Wu H, Shaukat A, et al. The potential therapeutic role of miR-223 in bovine endometritis by targeting the NLRP3 inflammasome. Front Immunol. 2018:9:1916.

24. Coll RC, Robertson AA, Chae JJ, Higgins SC, Muñoz-Planillo R, Inserra MC, et al. A small-molecule inhibitor of the NLRP3 inflammasome for the treatment of inflammatory diseases. Nat Med. 2015;21:248-55.

25. Coll RC, Hill JR, Day CJ, Zamoshnikova A, Boucher D, Massey NL, et al. MCC950 directly targets the NLRP3 ATP-hydrolysis motif for inflammasome inhibition. Nat Chem Biol. 2019;15:556-9.

26. Tapia-Abellán A, Angosto-Bazarra D, Martínez-Banaclocha H, de TorreMinguela C. MCC950 closes the active conformation of NLRP3 to an inactive state. Nat Chem Biol. 2019;15:560-4.

27. Hu X, Li D, Wang J, Guo J, Li Y, Cao Y, et al. Melatonin inhibits endoplasmic reticulum stress-associated TXNIP/NLRP3 inflammasome activation in lipopolysaccharide-induced endometritis in mice. Int Immunopharmacol. 2018:64:101-9.

28. Kelly P, Meade KG, O'Farrelly C. Non-canonical Inflammasome-mediated IL$1 \beta$ production by primary endometrial epithelial and stromal fibroblast cells is NLRP3 and caspase-4 dependent. Front Immunol. 2019;10:102.

29. Kong D, Fu P, Zhang Q, Ma X, Jiang P. Protective effects of asiatic acid against pelvic inflammatory disease in rats. Exp Ther Med. 2019;17:4687-92.

30. Feng $\mathrm{JH}$, Lee $\mathrm{HJ}$, Suh HW. The molecular signatures of acuteimmobilization-induced Antinociception and chronic-immobilizationinduced Antinociceptive tolerance. Exp Neurobiol. 2019;28:670-8.

31. Sun L, Liu L, Zong S, Wang Z, Zhou J, Xu Z, et al. Traditional chinese medicine Guizhi Fuling capsule used for therapy of dysmenorrhea via attenuating uterus contraction. J Ethnopharmacol. 2016;191:273-9.

32. Cheng Y, Chu Y, Su X, Zhang K, Zhang Y, Wang Z, et al. Pharmacokineticpharmacodynamic modeling to study the anti-dysmenorrhea effect of Guizhi Fuling capsule on primary dysmenorrhea rats. Phytomedicine. 2018; 48:141-51.

33. Leimert KB, Verstraeten BSE, Messer A, Nemati R, Blackadar K, Fang X, et al. Cooperative effects of sequential PGF2 $a$ and IL-1 $\beta$ on IL-6 and COX-2 expression in human myometrial cells. Biol Reprod. 2019;100:1370-85.

34. Oladosu FA, Tu FF, Hellman KM. Nonsteroidal antiinflammatory drug resistance in dysmenorrhea: epidemiology, causes, and treatment. Am J Obstet Gynecol. 2018:218:390-400.

35. Newton R, Kuitert LM, Bergmann M, Adcock IM, Barnes PJ. Evidence for involvement of NF-KB in the transcriptional control of COX-2 gene expression by IL-1ß. Biochem Bioph Res Co. 1997;237:28-32.

36. Perkins ND. Integrating cell-signalling pathways with NF-kappaB and IKK function. Nat Rev Mol Cell Biol. 2007:8:49-62.

37. Liu J, Tang J, Zuo Y, Yu Y, Luo P, Yao X, et al. Stauntoside B inhibits macrophage activation by inhibiting NF-KB and ERK MAPK signalling. Pharmacol Res. 2016;111:303-15.

38. Shen C, Zhang Z, Xie T, Ji J, Xu J, Lin L, et al. ViaRhein Suppresses Lung Inflammatory Injury Induced by Human Respiratory Syncytial Virus Through Inhibiting NLRP3 Inflammasome Activation NF-kB Pathway in Mice. Front Pharmacol. 2019;10:1600. 
39. Yin N, Gao Q, Tao W, Chen J, Bi J, Ding F, et al. Paeoniflorin relieves LPS induced inflammatory pain in mice by inhibiting NLRP3 inflammasome activation via transient receptor potential vanilloid 1. J Leukoc Biol. 2020. https://doi.org/10.1002/JLB.3MA0220-355R.

40. Wang Q, Ou Y, Hu G, Wen C, Yue S, Chen C, et al. Naringenin attenuates non-alcoholic fatty liver disease by down-regulating the NLRP3/NF-KB pathway in mice. Br J Pharmacol. 2020;177:1806-21.

41. Wang B, Wei H, Prabhu L, Zhao W, Martin M, Hartley AV, et al. Role of novel serine 316 phosphorylation of the p65 subunit of NF-kB in differential gene regulation. J Biol Chem. 2015;290:20336-47.

42. Yang CM, Chen YW, Chi PL, Lin CC, Hsiao LD. Resveratrol inhibits BKinduced COX-2 transcription by suppressing acetylation of AP-1 and NF-KB in human rheumatoid arthritis synovial fibroblasts. Biochem Pharmacol. 2017;132:77-91.

43. Tang SC, Liao PY, Hung SJ, Ge JS, Chen SM, Lai JC, et al. Topical application of glycolic acid suppresses the UVB induced IL-6, IL-8, MCP-1 and COX-2 inflammation by modulating NF-KB signaling pathway in keratinocytes and mice skin. J Dermatol Sci. 2017;86:238-48.

44. Maia H, Haddad C, Casoy J. The effect of pycnogenol on patients with dysmenorrhea using low-dose oral contraceptives. Int I Women's Health. 2014;6:1019-22.

45. Afonina IS, Zhong Z, Karin M, Beyaert R. Limiting inflammation-the negative regulation of NF-KB and the NLRP3 inflammasome. Nat Immunol. 2017;18: $861-9$.

46. Zhang $L Y$, Zhan $D L$, Chen $Y Y$, Wang $W H, H e C Y$, Lin $Y$, et al. Aflatoxin B1 enhances pyroptosis of hepatocytes and activation of Kupffer cells to promote liver inflammatory injury via dephosphorylation of cyclooxygenase-2: an in vitro, ex vivo and in vivo study. Arch Toxicol. 2019; 93:3305-20.

47. Hua KF, Chou JC, Ka SM, Tasi YL, Chen A, Wu SH, et al. Cyclooxygenase-2 regulates NLRP3 inflammasome-derived IL-1 $\beta$ production. J Cell Physiol. 2015;230:863-74.

48. Yang HH, Duan JX, Liu SK, Xiong JB, Guan XX, Zhong WJ, et al. A COX-2/sEH dual inhibitor PTUPB alleviates lipopolysaccharide-induced acute lung injury in mice by inhibiting NLRP3 inflammasome activation. Theranostics. 2020;10: 4749-61.

49. Zhang YF, Sun CC, Duan JX, Yang HH, Zhang CY, Xiong JB, et al. A COX-2/ SEH dual inhibitor PTUPB ameliorates cecal ligation and puncture-induced sepsis in mice via anti-inflammation and anti-oxidative stress. Biomed Pharmacother. 2020;126:109907.

50. Li G, Xia M, Abais JM, Boini K, Li PL, Ritter JK. Protective action of Anandamide and its COX-2 metabolite against I-Homocysteine-induced NLRP3 Inflammasome activation and injury in Podocytes. J Pharmacol Exp Ther. 2016;358:61-70.

\section{Publisher's Note}

Springer Nature remains neutral with regard to jurisdictional claims in published maps and institutional affiliations.

\section{Ready to submit your research? Choose BMC and benefit from:}

- fast, convenient online submission

- thorough peer review by experienced researchers in your field

- rapid publication on acceptance

- support for research data, including large and complex data types

- gold Open Access which fosters wider collaboration and increased citations

- maximum visibility for your research: over $100 \mathrm{M}$ website views per year

At $\mathrm{BMC}$, research is always in progress.

Learn more biomedcentral.com/submissions 